\title{
The Study on the Advance Mechanism of Economic Integration between Southwest China and Southeast Asia and South Asia Based on Border Effect
}

\author{
Niansong $\mathrm{Tu}^{1}$, Bei $\mathrm{Liu}^{2}$ \\ 1,2. Faculty of Management and Economics, Kunming University of Science and Technology, \\ Kunming,650093,China
}

E-mail: 13700672438@163.com; 907275920@qq.com

Keywords: border effect; Southwest China; Southeast Asia; South Asia; economic integration

\begin{abstract}
The development of South - South Economic Integration is lagging in both theoretic and practical aspects, therefore, the systematic and comprehensive study on it is necessary for discipline development and the needs of reality. This paper aims to investigate the needs of spatial economic integration from Southwest China and Southeast Asia, South Asia spatial economic integration. Based on the border effect, application of the new economic geography, along the driving direction of market force, government force and social force, the paper makes further study on the advance mechanism of spatial economic integration at three-force driving, and finds the spatial economic integration and development trend of Southwest China, Southeast Asia and South Asia. This paper explores the advance mechanism of economic integration of Southwest China, Southeast Asia and South Asia through three-force driving for decreasing negative shielding effect and increasing positive mediating effect. Finally, the paper puts forward the spatial economic integration suggestion for Southwest China, Southeast Asia and South Asia.
\end{abstract}

\section{Introduction}

Tieli Li (2005) put forward that the border effect is the impact of the border to cross-border economic behavior, which includes the shielding effect and the mediating effect. The shielding effect is the border effect to hinder spatial integration. Due to natural geographical barriers of the border area, especially the political and military confrontation, the border becomes an unbridgeable gulf of international economy and trade activities. The mediating effect is the effect that influences the space mediating effect of mutual contacts and exchanges. Both sides of the border always locate in the mountain, embrace the same water-source, originate from the same species and speak the same language, all these factors can promote the spatial interaction between both sides ${ }^{[1]}$. With the rapid development of regional economic integration, scholars at home and abroad pay more attention to the border effect. It becomes an important economic geographic problem that how to reduce the influence of national borders on the free flow of goods and elements and promote the process of spatial economic integration of Southwest China, Southeast Asia and South Asia on the condition that national sovereignty is guaranteed.

\section{The demand analysis of regional economic integration}

Regional economic integration is a regional economic unity which forms in accordance with economic relations, commodity flows, national cultural traditions, and social development. Regional economic integration is also a process which promotes the balanced development of regional economic unity by the regional flows of production elements on the basis of the regional division of labor and cooperation. The demands of regional economic integration generally arise from inside and outside. 


\subsection{Internal development motivation}

Firstly, Southeast Asia and South Asia are the developing countries and least developed regions. Since the new century, Southeast Asia and South Asia's overall situation tend to be stable, the internal requirements of national economic reform and development have been increasing. With the development of economic globalization, competition is becoming increasingly fierce. If the countries in this region are not united, the gap with other regions in the world will be larger and larger. Secondly, economy is the foundation of politics and the international alliance on political needs the economic alliance as insurance. The purpose of European cooperation is to obtain political union through economic cooperation, and achieve long-term stability and security in Europe. Developing countries have been gradually occupied a place in the world economy. However, as a single economy, they are still weak. Therefore, they need to protect their economic interests and economic security by participating in regional economic organizations. For political and economic considerations, the regional integration between Southeast Asia and South Asia countries is very urgent.

\subsection{The external pressure}

During economic globalization and integration, well-developing regional economic organizations like EU, NAFTA have emerged. The rapid development of these economic organizations makes the North-South gap bigger, and also brings the greater pressure on the countries and people in Southeast Asia and South Asia. The developments of ASEAN and SAARC promote cooperation and exchanges in the regions, but the scope of cooperation and the level of development remain to be further expanding and deepening. Furthermore, a series of events such as the financial crisis in Southeast Asia in 1997 and the blocked Doha Development Agenda in WTO, made the Southeast Asia and South Asia countries realize the necessity of regional economic integration more and more urgent.

Southwest China is geographically contiguous to Southeast Asia and South Asia, so the advantage of border area is clear. Southwest China should use the advantages to accelerate the development and become the bridge and link which connect the world three major economic circles - China Economic Circle, Southeast Asia Economic Circle and South Asia Economic Circle.

\section{Feasibility analysis of regional economic integration----Three-force model}




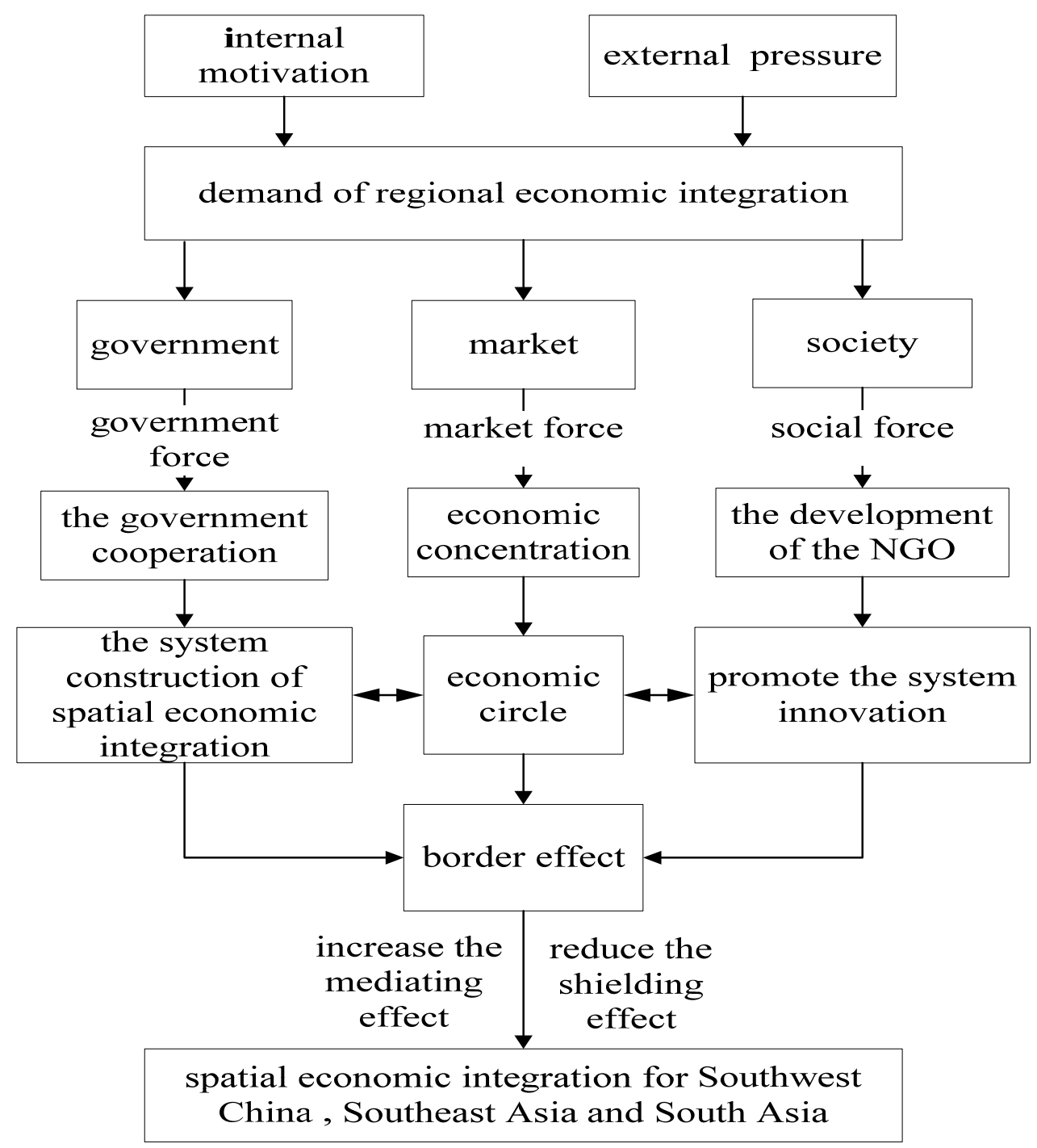

Figure 1.The advance mechanism of spatial economic integration based on border effect

As stated above, Southwest China, Southeast Asia and South Asia are faced with internal and external pressure, so their economic integration needs are strong. Under the huge demand of economic integration, the three-force model is formed by market force, government force and social force $^{[2]}$.

\subsection{Market force}

There are many factors to promote regional economic integration, but the most fundamental is the inherent requirements of economic development, which is market force. Under the conditions of market economy, enterprises are the main activities, as for any economic actor, if it can not get the interests of the return, it will not be able to survival and development. Thus, the pursuit of profit maximization is the intrinsic motivation of all economic actors ${ }^{[3]}$. Market force can be effective in promoting regional economic cooperation and exchanges, in expanding the in-depth cooperation of the South - South economic, and in realizing economic agglomeration effect ${ }^{[4]}$.

\subsection{Government force}

Government force in promoting regional economic integration and cooperation should be reflected in the three levels. Firstly, to foster the market system and market mechanisms for regional cooperation development, promote the perfection of market system and create a more mature marketing economic system environment by formulating relevant laws and regulations; Secondly, to play an active service and policy guidance role in promoting enterprise cooperation across the region; Thirdly, to coordinate the interests of inter-district effectively ${ }^{[3]}$.

\subsection{Social force}

Social force should strengthen the development of non-governmental organizations and groups to enhance understanding of the economic, cultural, and social habits of the people of Southwest 
China and the surrounding areas, in order to facilitate enterprises to make the right decisions. Then, it should cooperate with the government's public management, play its maintenance border stability, environmental protection, social progress, and other functions, so as to promote institutional change to promote regional economic integration.

Through the three-force model, we can use positive measures and means to improve the beneficial mediating effect continuously, to reduce the adverse shielding effect.

\section{Conclusions and recommendations}

In summary, in the face of the trend in the development of economic globalization and regional economic integration, Southwest China, Southeast Asia and South Asia can not turn a blind eye ${ }^{[5]}$. There are three proposals: Firstly, to deepen economic cooperation, expand trade and strengthen ties, as market force can play a leading role in the economic integration. Secondly, to start building political mutual trust, seek common ground, enhance friendship, play the guiding role of the government force in the spatial economic integration. Thirdly, to strengthen cultural exchanges, close relationship, let social force play a role in promoting the spatial economic integration.

I believe, in the push of the three-force consisting of market force, government force and social force, the shielding effect will reduce ceaselessly, the mediating effect will increase gradually in Southwest China, Southeast Asia and South Asia, and the regional economic integration will achieve even greater development.

\section{Acknowledgements}

This research is supported by the National Natural Science Foundation of China named "Statistical Inference for Joint Mean and Variance Models with Complex Data" (No. 11261025/A011103).

\section{References}

[1] Tieli Li, Huaiyu Jiang. Sub-regional economic cooperation mechanisms: the analytical framework of a border effect [J]. Northeast Asia Forum 2005, (3):90-94

[2] Shengda He. China - ASEAN Free Trade Area of Southwest China provinces opening up [M] Kunming: Yunnan People's Publishing House, 2007.p78

[3] Dingkun Cai, Huasong Luo. Study on regional economic cooperation mechanism in Yunnan China and India [J]. South Asian Studies Quarterly, 2010, (1):81-82

[4] Shuanglu Liang. China border effect of integration and economic growth center formation based on the spatial economic theory of explain [J]. Inquiry Into Economic Issue, 2008, (1):31

[5] Shilu Wang. Report of Southeast Asia (2008-2009) [M]. Kunming: Yunnan University press, 2009 